\title{
Smart specialization strategies as a case of mission-oriented policy-a case study on the emergence of new policy practices
}

\section{Dominique Foray*}

Ecole Polytechnique Fédérale de Lausanne, College of Management, ODY Station 5, EPFL, Lausanne 1015, Switzerland. e-mail: dominique.foray@epfl.ch

*Main author for correspondence.

\begin{abstract}
This article involves a conceptual evaluation of a large-scale innovation policy experiment-so-called smart specialization strategies (S3s) - that took place within the framework of the European regional cohesion programs between 2011 and the present. The goal is to provide a collection of reflections offering a wealth of lessons and information regarding the capacity of regional governmental agencies and other actors involved in the innovation system to implement a mission-oriented research and development support program and regarding the institutional and cultural conditions that can facilitate its practical application. In the first section, I briefly review the fundamentals of S3s. In the second section, I propose a framework for the identification of mission-oriented policies and I explain how S3 fits into this category. The following section shows how this policy represents a break with the policies that have long dominated the regional policy landscape. The fourth section describes the designing of this policy whose objective is to make strategic choices and decentralization of information and initiatives compatible. And finally, the last section reports on the emerging institutional forms that seem to facilitate the putting into practice of this design.
\end{abstract}

JEL classification: 025, 031, 038

This article may be considered as a conceptual evaluation of a large-scale innovation policy experiment that took place within the framework of the European regional cohesion programs between 2011 and the present. ${ }^{1}$ In the position of privileged observer-contributor, and taking into account the fact that systematic evaluations of the effects of this policy will not be carried out for several years, I think I am able able to provide a collection of reflections offering a wealth of lessons and information regarding the capacity of regional governmental agencies and other actors involved in the innovation system to implement a mission-oriented R\&D support program (abbreviated as missionoriented policy [MOP]) and regarding the institutional and cultural conditions that can facilitate its practical application.

1 Having been at the origin of the S3 concept, with Bart Van Ark, Paul A. David, and Bronwyn Hall, then deeply involved in putting the recommendations resulting from this approach into practice, I have greatly contributed to developing the design of this policy at a theoretical level, to the translation of this design in terms of policy practices intended for regional agencies, and finally to the concrete shaping of the "institutions" conceived for implementing these practices. 
In the first section, I briefly review the fundamentals of smart specialization strategies (S3s). In the second section, I propose a framework for the identification of MOPs and I explain how S3 fits into this category. The following section shows how this policy represents a break with the policies that have long dominated the regional policy landscape. The fourth section describes the designing of this policy whose objective is to make strategic choices and decentralization of information and initiatives compatible. And finally, the last section reports on the emerging institutional forms that seem to facilitate the putting into practice of this design.

\section{Smart specialization strategies: a primer}

\section{$1.1 \mathrm{~S} 3$ as a key instrument for European Union regional policy}

One question that has been repeatedly addressed for the past 20 years in regional policy discussions is whether there is a better alternative to a policy that spreads research and development (R\&D) investments thinly across several frontier technology and research fields, and as a consequence fails to make much of an impact in any one area. A more promising strategy appears to be to encourage investment in programs that will complement the country's other productive assets to create future domestic capability and interregional competitive advantage. We had termed this strategy "smart specialization" (Foray et al., 2009; Foray, 2015). Smart specialization is expected to create more diversity among regions than a regime in which each region tries to create more or less the same in an imitative manner. The latter would almost certainly result in excess duplication of R\&D and educational investment programs, which in turn would diminish the potential for complementarities within the European knowledge base (Foray et al., 2009).

Based on our article (Foray et al., 2009), the smart specialization approach was integrated into the reformed cohesion policy for 2014-2020. Member states and regions have developed over 120 S3s, establishing priorities for research and innovation investments for the 2014-2020 period. Throughout this period, more than EUR 40 billion (and more than EUR 65 billion including national co-financing) allocated to regions via the European Regional Development Fund will fund these priorities (European Commission, 2017).

To ensure the application and diffusion of the S3 approach across regions in Europe, S3s need to be in place ("exante conditionality") before receiving the financial support of the European Regional Development Fund on research and innovation in the 2014-2020 period.

Moreover, to support the process, the Commission set up an S3 platform, which, since 2011, advises regional authorities on how to design and implement their S3.

\subsection{From the formation of transformative activities to structural changes}

The concept of smart specialization describes a process. A process aimed at transforming the economic structures of a region or any other geographical unit through the formation and development of new transformative activities.

Transformative activity is a key concept. It is neither an individual project nor a sector as a whole but rather a collection of innovation capacities and actions, that have been "extracted" as it were from an existing structure or several structures, to which can be added extra-regional capacities and that is oriented toward a certain structural change.

The following case will help readers understand the notion of a transformative activity leading to structural change. This concerns the footwear industry in Northern Portugal, which has undergone profound renewal in a context of frantic global competition. The strategy implemented by the public innovation agency involved the formation of an activity aimed at the development of new forms of flexible automation in the footwear industry. The goal was to achieve the integration of engineering knowledge from the University of Porto (INESC); skills of companies specialized in industrial machinery, tools, and software; as well as the entrepreneurial vision of a few footwearmanufacturing firms that had a good understanding of the urgent need for revival via innovation. The integration of this knowledge facilitated the exploration of the potential for automation associated with advanced cutting tools to increase the flexibility and quality of production. Economic experimentation with these technological developments resulted in a new business model based on an increase in the variety of designs and the capacity to rapidly respond to small orders. This development has led one segment of the footwear industry in Northern Portugal to bypass global competition and become the second most important European producer in terms of exports and added value (Agencia de Inovaçao, 2012). 
In this case, the starting point is an existing structure, the transitional path is the formation and development of a transformative activity, and the objective is a structural change (here the modernization of a traditional sector). We also observe that the transformative activity does not necessarily concern the whole sector but a group of companies, suppliers, and research partners that are prepared to embark upon some forms of collective action to transform their capacities.

A transformative activity concentrates the necessary actions-R\&D projects, partnerships, and supply of new specific public goods- to explore the new area of opportunity and facilitate the implementation of collective actions between the different innovation actors concerned. The basic operational mode is not necessarily the collaborative project but the search for coordination and links between the entities and projects concerned, which will facilitate spillovers, economies of variety and scale, and the supply of specific public goods and infrastructures to the domain in question.

In some cases, the development of a new transformative activity can occur in a spontaneous and decentralized way, with great success. It is triggered by entrepreneurial capabilities as well as the manager's understanding and vision that collective or coordinated actions can boost innovation and profitability (Ghemawat, 2017). Such development is likely to generate knowledge spillovers and stimulate the entry and agglomeration of firms around the new activity. There are many smart specialization stories that were successful without any policy.

But in many cases, entrepreneurial and management capabilities are too weak, or perhaps the challenges of developing a new transformative activity to explore new combinations between capacities and opportunities through some kind of collective actions are too great, and the processes described earlier will not happen, at least not in a spontaneous way. A policy is required to help identify a transformative activity that is needed to trigger a structural change and support the growth of such activity.

Based on these definitions, designing a $S 3$ means identifying a small number of transformative activities, which will be developed and supported. This portfolio of activities is managed at a regional level and possibly modified as new opportunities for structural change arise.

\subsection{Differentiation and specialization}

In identifying and supporting new transformative activities, regions can address a dual problem-that of differentiation and specialization of their innovation capacities—-that is generally poorly dealt with by standard innovation policies.

\subsubsection{Differentiation}

Each region is different with regard to its history, relative specializations, and socioeconomic, geographic, and demographic conditions. These differences imply that each region can be characterized by specific capacities, needs, and opportunities concerning research and innovation that cannot be completely fulfilled within the framework of undifferentiated policies, which are limited to the provision of aggregate and generic capacities. Each region is therefore invited to particularize itself by identifying some new key domains to explore new combinations between capacities and opportunities and in which regional innovation capacity must be established or strengthened.

\subsubsection{Specialization}

This logic of differentiation necessarily implies certain forms of specialization. We have already highlighted that such a policy involves addressing specific capabilities and infrastructures, and a regional government whose governance capacities are, by definition, limited will not be able to achieve this for all sectors. Choices must be made. Furthermore, essential determinants of the productivity of activities dedicated to innovation are scale, critical mass, and a sufficient agglomeration of actors. It is problems of indivisibility and methods of circulating and recombining ideas and knowledge that give large-scale systems—-for example, urban centers—an indisputable comparative advantage when it comes to innovation. Thus, each region will be well advised to possess some kind of critical masses of in-

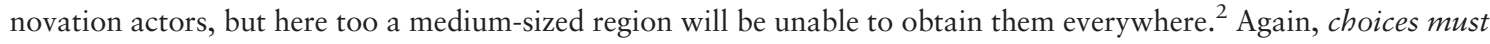
be made.

2 Critical mass is a relative measure. The absolute amount of resources that need to be invested to boost innovation depends on many factors that are specific to the technological field or industry involved (Trajtenberg, 2002). In some 
In many cases, regional policies fail to boost innovation and structural changes because they promote specialization without differentiation or differentiation without specialization. The former involves the promotion of a cluster (specialization) that does not reflect any regional-specific strengths or potentials. Such a policy could be labeled "another biotech cluster," reflecting the tendency of regions to try to specialize in the same high technologies. The "another biotech cluster" policy has been the result of undifferentiated recommendations regarding best policy practices encouraging policymakers to set their sights on doing the same good things to foster the same forms of innovation.

The latter case involves subsidizing an isolated project, which is disconnected from the existing product space of the regional economy. Such a policy could be labeled "I subsidize your drone R\&D project although it is not related to any other R\&D activity in the region." The absence of local connections and potential agglomeration will make the public funding of such a project a very risky venture (the project is either likely to fail or, if successful, to move to a place where it will benefit from better connections and relations with the environment).

Contrasting with these incoherent policies, two other logics provide a better understanding of what should be supported and promoted to boost innovation and structural change at a regional level: policies with neither a goal of differentiation nor a goal of specialization are the standard and horizontal policies that are of course very useful for building generic capacities and improving framework conditions. Policies pursuing both goals of differentiation and specialization express the idea of smart specialization in which the two goals are characterized by strategic complementarities: the social benefits of achieving one goal increase when the other goal is also achieved.

\subsection{The centrality of the priority identification process}

John Enos wrote very pertinently-long before the era of smart specialization-that it is useful and productive for regions to put more effort into discovering and choosing, in detail and for the future, priority areas for R\&D and innovation (Enos, 1995). There are two reasons for devoting more effort to specifying what are likely to be and what are not fruitful priority areas. The negative reason is that if regions do not specify, global players will; the positive reason is that the knowledge and experience acquired from discovering and choosing the right directions for R\&D and innovation can be valuable in carrying out the subsequent stages of product/process/market design, production, and distribution.

The idea is therefore that the process by which priorities and transformative activities can be identified is not a process on which resources must be economized or that should be speeded up at all costs. Neither is it a process that should be "confiscated" by the government. But it is a process of learning about the capacities and opportunities specific to the region's economy that is useful and productive. And as such, it lies at the very heart of S3.

\subsection{S3: addressing specific capabilities and specific coordination problems}

$\mathrm{S} 3$ is characterized by a key fact, which is that it has to address specific problems and needs, according to the technology or sector considered. Indeed, the construction or development of a transformative activity specific to a sector or technology entails the provision of innovation services and infrastructures that are themselves specific to this domain and the fulfilment of needs for coordination between actors that are also specific. This is essentially because innovation requires not only general framework conditions and aggregate capacities— the basics have to be right-but also capabilities and infrastructures that are specific (not generic) to the domains, sectors, or technologies to which the innovation is related.

Supporting biotechnology development for fisheries will require the provision of capabilities in terms of research, suppliers, and services very different from those required to support the development of advanced manufacturing technologies for the footwear industry or to support the development of Information and Communication Technologies (ICTs) for tourism. Each transformative activity thus in fact corresponds to a particular policy. Such a policy has to deal with the complexity and specificity of each activity and this has a cost. This is haute couture rather than ready-to-wear. A policy such as $\mathrm{R} \& \mathrm{D}$ tax credit is ready-to-wear (it has a cost but is relatively easy to implement), whereas providing the specific capabilities for a specific emerging activity is haute couture and therefore more costly still.

cases, the amount of resources is likely to be huge (and thus not attainable by any medium-sized region). In other cases, this amount of resources is not "big," as for instance in regions specialized in the co-invention of ICT applications for a specific sector (see next endnote). 
But according to Hausmann and Rodrik (2006), it is unavoidable. Innovation policy cannot be limited to the provision of generic capabilities and infrastructures: "The idea that a Government can disengage from specific policies and just focus on general framework conditions in a sector neutral way is an illusion based on the disregard for the specificity and complexity of the requisite publicly provided inputs and capabilities in specific domains."

\subsection{Three qualifications}

We must now present three qualifications to avoid certain incorrect interpretations of this approach.

First, the logic of smart specialization does not mean that "all the rest" should be neglected. The most generic and horizontal policies naturally remain essential, and smart specialization becomes an additional option that regions are well advised to activate if they are capable of setting up an intelligent process of identification of priorities (i.e., transformative activities) and development of these activities.

Second, the logic of regional differentiation of innovation capacities, needs, and opportunities at a regional level necessarily implies that the reality of innovation is not reduced to high-tech and cutting-edge research. Innovation is widely distributed over the whole spectrum of sectors (not just high tech) and invention processes (not only formal $\mathrm{R} \& \mathrm{D})$. For many regions, the point is not inventing at the frontier but rather generating innovation complementarities in existing sectors. These types of complementarities are perhaps less exciting and flamboyant, but they ultimately represent the key to economy-wide growth in regional economies. This means that a transformative activity, depending on what the objective of transformation is, can involve actions like training programs, the formation of new managerial and engineering skills, quality control and certification processes, as well as technology adoptionall these actions are perhaps less ostentatious than supporting high-tech start-ups but are the components of a coherent and full-fledged transformative activity aimed at profoundly transforming the structures of traditional industries. $^{3}$

Third, the identification and support of transformative activities do not mean that the aim of S3 is a closed economy or regional autarky. The strategy is open. It must take into account and be based on existing potential, part of which, in each region, is composed of international investments and segments of internationalized value chains. It must also seek critical resources and knowledge outside the region that are not available at home.

\section{Why talk about MOPs in connection with S3?}

It is not easy to distinguish from the mass of policies devoted to research and innovation a clearly defined subsection, which could comprise such diverse MOPs as exploring Mars, reducing poverty, stabilizing the climate, discovering a new vaccine, or modernizing the agro-food sector in Lombardy! And yet it certainly seems that there is a "mission" entrusted to each of these programs.

It is indeed difficult to try and define this category by the nature of the missions that would be assigned to these policies. There is an extremely wide variety of possible missions-in terms of functional objectives and of the level of aggregation or granularity at which these missions are identified—as many missions all interlock. It is thus helpful to try to identify what characterizes MOPs in a more analytical fashion and we have chosen the resource allocation framework that prevails in the case of these MOPs.

First, the MOP is distinguished by its non-neutral nature, in other words a principle of preferential intervention. This logic of non-neutrality means there is a predetermination of a technological domain, sector, or class of economic agents that are specifically targeted by the intervention in question. In contrast, a sector-neutral (horizontal) policy is

3 The specific properties of general purpose technologies (GPTs) play an important role in helping secondary regions to combine their existing capacities with new opportunities (Bresnahan, 2010). Central features of a GPT are horizontal propagation throughout the economy and complementarity between the invention of the GPT and the development of applications that are related to specific sectors. Moreover, the dynamics of a GPT may be spatially distributed between regions specialized in basic inventions and regions investing in specific application domains that are related to existing structures. Although a few leading regions can invest in the invention of a GPT or the combination of different GPTs (such as bioinformatics), follower regions and laggards are often better advised to invest in the co-invention of applications, i.e., the development of the applications of a GPT in one or several important domains of the regional economy. 
a policy that addresses problems that are similar to those of any company and other innovation actors across sectors and fields. Such a neutral policy aims at improving general conditions and fixing generic problems, while avoiding any preferential interventions, thus minimizing the risks of distortions and government failures. The problem is that there are in fact very few perfectly neutral policies, as expressed so well by Rodrik (2007), who speaks of "limiting case more than a clear-cut alternative to sectoral policies." For example, R\&D tax credit—often considered the panacea of neutral innovation policies-is actually an intervention in favor of companies doing research. Purely neutral policies would therefore more accurately be those that do not directly concern innovation but concern more generally generic capacities and institutions, which form the innovation framework-human capital, functioning of the different factor and product markets, macroeconomic environment, as well as the generic capacities and institutions that form the essential components of an innovation system (university, intellectual property, bank, etc.), even if the neutrality of each of these institutions—in other words, their general validity—is never absolute.

As most innovation policies are thus non-neutral, we need a second criterion in terms of allocative logic to pinpoint more precisely what constitutes the specificity of MOPs. This second criterion is based on the idea that innovation policy can either influence the rate of innovation without being concerned about the domains where a higher rate would be desirable or it attempts to influence the direction of innovation.

By direction, we are not referring here to the theory of the induced technical change-according to which the direction of technical progress varies as a function of relative price changes-as direction in this case expresses simply factorsaving logics (labor-, capital-, and energy-saving). When we talk of direction here, we mean rather the fact of aiming at certain technological, social, environmental, or industrial objectives, which entails targeting specific domains-whether industrial or technological—and the actors connected with them (see also Mazzucato in this issue).

Thus, a non-neutral policy that is limited to influencing the rate of innovation will focus on general categoriesactivities (R\&D) or actors (Small and Medium Enterprises (SMEs)) — regardless of their sectoral or technological affiliation. A non-neutral policy focusing on innovation rates will create a kind of cross section in the innovation system to target a predefined category-SMEs, firms doing research, etc. For example, the Small Business Innovation and Research Program (SBIR), an American program primarily intended for small firms, like the R\&D tax credit, are non-neutral policies focusing exclusively on the rate of innovation.

A policy focusing on the direction of innovation is, by definition, non-neutral. But also, it is characterized by objectives that go beyond the simple fact of offering preferential assistance to a certain category of actors. It is designed according to specific technological, industrial, social, or environmental objectives, whose fulfilment requires clusters of innovations oriented in the appropriate direction. Whether they are aimed at exploring Mars, reducing obesity problems, or modernizing a particular traditional industry, these policies will obey the same principles of non-neutrality of interventions and direction of innovation. These principles form the basis of the MOP concept. Below we represent, in a tree diagram (Figure 1), a classification of innovation policies according to allocative logics (neutrality or non-neutrality, rate or direction).

The advantage of this taxonomy is especially to show that all non-neutral policies are not MOPs. There is in particular a class of non-neutral policies that exclusively target the rate of innovation (center sphere) that are relatively easy to implement, as they focus on the resolution of "standard" problems, the category of actors targeted is simple to define, the policy instruments are relatively easy to use, and the program administration costs are relatively low.

A significant difference within non-neutral policies between those that target simply a category of actors or activities (center sphere) and those that focus on certain technological or other objectives (left sphere) is that the latter inevitably have a systemic character (David, 1993). They must indeed address questions of complementarities between different types of capacities, coordination between actors and between investments, or connection between innovation and diffusion. All these problems are only weakly addressed by a policy that focuses on only one particular category of agent or activity. ${ }^{4}$

Policies that are non-neutral and target the direction of innovation-MOPs-are marked by a higher degree of intentionality and prioritization. The predetermination of the targeted objectives and domains is no easy matter; it

4 David (1993) distinguishes between the stage model of innovation policy (which tends to characterize the policies in the central sphere that focus on certain stages or certain actors of the innovation process) and the systems model of innovation policy that recognizes the importance of questions of complementarity, coordination, and connection between innovation and diffusion and thus characterizes MOPs. We should note that the system approach is also prevalent in the right sphere of Figure 1 but as a complement to a neutral resource allocation logic. 


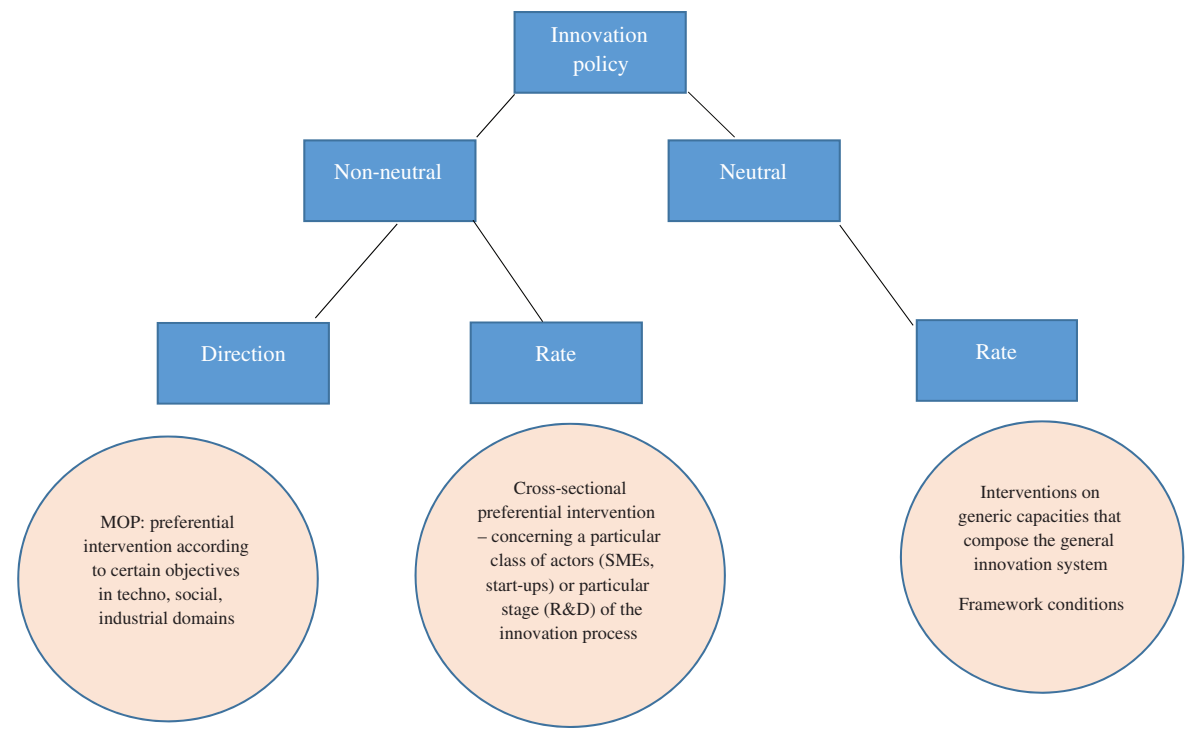

Figure 1. A taxonomy of innovation policy based on a resource allocation framework.

requires the setting up of complex strategic choice processes. Furthermore, the degree of specificity of interventions is higher than in the other two policy categories. Indeed it is specific problems of complementarity and coordination that have to be addressed-the level and quality of the information required are often out of the range of government or public agency (we will return to this very important point in Section 3). The instruments necessary for interventions are not standard and will vary according to the objectives, sectors, or technologies concerned. The administrative cost of such programs is higher.

The MOP sphere (left) is relatively extensive. It encompasses all policies whose starting point is a specific objective of a technological type (explore Mars or develop new batteries), an industrial type (develop a new industrial specialization, modernize a traditional sector, or generate a high-tech sector), a social type (eradicate malaria or combat obesity), or an ecological type. All these objectives involve, by definition, the principles of non-neutrality (preferential intervention) direction (predetermination of domain) and the adoption of a systems approach. S3s, as a policy aimed at generating new so-called transformative activities within a region (Section 1), form an integral part of this MOP sphere, as they are essentially determined by these principles of non-neutrality, direction, and systems approach.

These principles of non-neutrality and direction, as well as the systemic vision that must be adopted, obviously impose substantial constraints and challenges in terms of policy design and policy governance, particularly to minimize the risks inherent to these principles. Our next sections are to a great extent devoted to these questions that have been posed in the case of S3.

\subsection{From "old" to "new" types of missions}

The MOPs that are crucial now, while posing unprecedented design and implementation problems, are not those aimed at inventing a new technological object or crossing a particular line regarding exploration or discovery. Those policies are as old as the hills and although they are a means of confronting the greatest technological challenges, they do not pose very complex problems in terms of institutions, incentives, and organizations. Likewise sectoral policies aimed for example at maintaining a sector regarded as being strategic can also not be considered new. We will leave all that aside. The policies that are really new and do pose unprecedented problems concerning design and implementation are those that focus on the development of new activities targeting the transformation of economic or technological structures-whether these activities are intended to address a grand challenge (like climate change), or are aimed at developing a high-tech sector (ICT) or enabling a region to create new "specializations" (smart specialization). 
Within this more limited framework of analysis, the expression "capacity to implement a mission-oriented policy" covers not only centralized strategic decision-making, governance, and evaluation capabilities. It particularly concerns the fact of being able to reconcile a logic of strategic choice, selection, and establishment of priorities with a logic of decentralized and entrepreneurial information and initiatives. It is this conciliation between two logics, in the past too often seen as contradictory, that today forms the basis of what we will call the new MOPs—of which S3 is one. Achieving this conciliation is however a delicate undertaking—entailing the invention of a policy design based on concepts such as level of granularity (at which priorities are established), entrepreneurial discovery, or flexibility-and necessitating relatively new institutional and organizational forms (at least in the case of regional policies) to put this design into practice.

\section{S3 as part of a new class of policy programs}

The regional innovation system approach was of course a valuable development, recognizing the need to build an institutional framework for innovation at a regional level, but this approach remained largely neutral and undifferentiated regarding regions' specificities (right sphere in Figure 1 above). There were naturally exceptions, but sectorneutral policy was the main logic underlying resource allocation in the framework of regional and cohesion policy.

S3 has a very different logic. It is non-neutral and focuses on the direction of innovation. A major difference vis-à$v i s$ the traditional regional policies is a higher degree of intentionality, centralization, prioritization, and commitment to new "specialization."

As such, S3 as well as other policies involving choices and preferential interventions have been seriously criticized. There are four main critical arguments that are important to consider. All these skeptical views about S3 and other MOPs merit attention because they will contribute toward designing a policy process to minimize the problems identified below. ${ }^{5}$

The first kind of skepticism is the classic Chicago concern about distortions: "Although it is certainly true that not everything can be done at once, focus on selected areas for large investments to the neglect of the rest of the economy is a highly questionable strategy. Why it would be preferable to allocate scarce capital so that some activities have excellent infrastructures while others must manage with seriously deficient structure is not clear: without further evidence, it would appear to be a distortion." Krueger (2012) comments here on the works of Justin Yfu Lin, a great promoter of the new structural economics framework. She would have plausibly expressed the same objections to smart specialization policy. Ann Krueger is part of this large group of economists who recognize theoretically the existence of market failures (as a necessary antidote to the formal theory of general competitive equilibrium; Winter, 2017), but strongly argues that these market failures are not sufficiently serious to warrant governmental intervention and, in particular, preferential policies that discriminate across activities.

The second kind of skepticism deals with a particular case of distortion, generated by a systematic allocative bias in favor of the high-tech sector. Policies aimed at promoting rocket science and high-tech entrepreneurship will possibly have an inclusive effect in the long term thanks to the habitual macroeconomic sequences-as described for instance by Phelps (2006) —or because of the potential effects of innovation on social mobility so well described by Aghion (2016). However, generally speaking, such positive effects on inclusion will only be realized in the long term, whereas in the short term, such policies are essentially discriminating and exclusive and will to a great extent benefit talented students from a few of the best campuses-assisted and supervised by very selective financial actors. Based on a high-tech policy only, entrepreneurial activities are going to be stimulated and this will be beneficial to a small part of the regional economy-a few indicators will improve and not the least important ones (patent, Venture Capital (VC) attractions, and highly skilled jobs)—but the inclusion effect will be negligible and the gap between the dynamic part and the non-dynamic part of the economy will increase.

The third kind of skepticism deals with government capabilities to understand and fix coordination failures that are specific to each sector or technology. As well argued by Matsuyama (1997), "Understanding the basic principles of coordination problems does not take one very far in the direction of useful, practical conclusions about how to

5 We do not mention here the classic and somewhat generic problem that is about project or research area selection (to minimize the risk of supporting projects that would have been undertaken anyway, turning the policy into a simple mechanism of transfer of funding from the public to the private sector, without any additional effect. Indeed this problem applies both to neutral and non-neutral policies). See Stiglitz and Wallsten (1999). 
construct technology policy. Understanding the basic problems, one is led to a new but not simpler set of questions: What activities in what firms are complementary and need to be coordinated and in what way? An appropriate choice of policy tools requires a detailed understanding of the externalities and the innovative complementarities involved." This is obviously a relevant comment but should it be taken as an argument to stop any policy intervention aimed at addressing specific capabilities and specific infrastructures to support the formation of a specific transformative activity (Aghion et al., 2009)?

The fourth skeptical view is that any pretext given to the government for setting priorities and establishing strategic targets increases the risk that the whole policy will become a central planning exercise based on a principalagent governance and resulting in very poor information flows from the bottom. Rodrik (2013) puts the argument very well: "The agency framework assumes that the principals already have a very good idea of what needs to be done to achieve public goals, and all that needs to be done is to provide the agents (firms) with the right incentives to carry out the requisite investments." However, to be fair, Rodrik is not using it against industrial policy but as an argument in favor of a new industrial policy design.

The fifth skeptical view can be applied to any policy logic—non-neutral and neutral alike. However, the problem identified is likely to be amplified in the case of a policy involving preferential interventions. This is Romer's argument: it is not enough to increase spending on $R \& D$ but what needs to be supported is the total quantity of inputs that go into R\&D: "In fact, any generous subsidies will fail in adding more R\&D if the supply curve of human capital is fixed and was not adjusted through early training programmes. In such case the increase of demand for R\&D induced by policy will translate into a proportional increase in wages for R\&D scientists with no increase in the level of R\&D activities" (Romer, 2000). Romer rightly emphasizes here the importance of a correct sequencing of policy programs. But whereas this problem of equating human capital with an increase in the demand for R\&D can be attenuated within the framework of a neutral policy by reallocating jobs between industrial sectors, it will be far more difficult if the increased demand for R\&D caused by the policy concerns a specialized domain.

Responses to these skeptical arguments can be provided at two levels: at an abstract level at which a policy design is elaborated and at a more practical level at which institutional conditions for design implementation are discussed.

\section{Policy design}

Responding to these skeptical arguments by formulating a policy design appropriate to MOPs is crucially important. The literature in this domain is not very well developed however. There are works that provide certain indications indirectly by studying historical cases of MOPs in different sectors, from which certain good (and bad) practices can be deduced (Mowery and Simcoe, 2002; Henderson and Newell, 2010; Jaffe, 2011; Mazzucato, 2011; Foray, et al., 2012). There is also the still small number of works that identify from an econometric point of view certain success factors of sectoral industrial policies—-for example, the nature of competition in the targeted sector (Aghion, 2016). And there are also the works dealing with the design of particular instruments, which can possibly be used within the framework of MOPs (Kremer and Williams, 2009; Murray et al., 2012). Finally we must recognize the very significant contribution made by Rodrik and a few others (Sabel and Haussman) who have gone furthest in the analysis of appropriate policy designs as far as industrial policies in development economics are concerned.

In comparison with all these works, our contribution on the search for an appropriate policy design for S3 is original even if significantly inspired by the works of Rodrik. It identifies the three major problems that any targeting and strategic policy prioritization is likely to encounter and that are the source of the different kinds of skepticism mentioned earlier:

how to go about establishing priorities,

how to develop transformative activity within the framework of the established priority, and

what are the implications of a policy that is by its very nature experimental,

and suggests solutions and principles of policy design—based on the literature that we have briefly alluded to and the detailed and meticulous observation of the trials and errors experienced in the context of the setting up of S3.

It must be noted that there is no one precise design component responding to one particular skeptical argument. We think that it is rather the design as a whole, based on various principles such as the concepts of transformative activity, granularity, entrepreneurial discovery, and flexibility, which should be considered to address the various criticisms mentioned earlier. 


\subsection{Establishing priorities}

Regardless of the type of MOP, strategic priorities and choices must be established. This is the rule for a non-neutral policy. How can this process be made as innocuous as possible, which means in particular minimizing policy capture problems and avoiding the monopolization of resources by a small number of motivated actors? There are two principles that seem to us to be important.

First, the level of granularity: the selection of priorities must be carried out not at a sector level but at the level of activities that transform these sectors or establish new ones. This level—known as transformative activities-is thus one of intermediate granularity, finer grained than sectors but coarser grained than individual entities. For example, a "correct" priority should not be the footwear industry as a sector but rather the development of flexible manufacturing technologies for the footwear industry, should not be agro-food but the development of nano-applications to increase quality in agro-food, should not be energy but the development of smart materials for the renewable energy sector, etc. This is the level that best reveals the domains in which a region should position itself. This intermediate level of aggregation also allows the defining of priority domains that are not too extensive. In an area that is too broad-one designated "energy" for example—the 12 or 15 projects that are selected and supported are scattered and dispersed. Connections, synergies, and spillovers will hardly happen and critical mass will not emerge. In a narrower priority area, the same number of projects will be more connected, providing potential scale, scope, and spillover effects. Some platforms will be "general-purpose" and the markets for specialized inputs (skills and services) will become thick. There is, of course, a political rationale underlying the need for broad areas (the so-called "coffee for all"), but this is not the right way to proceed because, at the end of the day, the region will not get what an S3 is supposed to deliver.

Second, intensive interactions between public and private sectors created within the framework of a robust and transparent process: the identification of transformative activities is based on a process of interactions and dialogue between the government, public sector, and private sector, backed up by evidence concerning the regional economy and knowledge concerning the region's entrepreneurial activities and capacities. There is no magic solution to avoid problems of policy capture by "regulars" and those with the most influence. In the context of S3, it is a question of setting up a decentralized and transparent process to identify the desired structural changes, the transformative activities that could lead to them, and the capacities and potentials that enable the selected activities to be initiated in a credible manner. All of this contributes to the selection of a small number of unique combinations between existing capacities and new opportunities for transforming regional structures.

\subsection{Developing a transformative activity}

Once a priority (a transformative activity) has been identified, the standard modus operandi for policy is to deploy all sorts of policy instruments to support the exploration of the new area of opportunities and provide the specific public goods that are needed (training, basic research, and services) as well as coordination devices to assist the formation of networks and partnerships. There is nothing new here: R\&D and human capital policy tools as well as cluster policy tools can be deployed, but there is an important qualification: these tools address the specific development of a quite narrowly defined activity aimed at a particular structural transformation. Three design principles must be respected:

First, consideration of the complementarities between human capital and demand for $R \& D$-a principle that directly resolves Romer's problem—spending more on formal R\&D may end up inflating wages of R\&D personnel and not producing more innovation-and thus focuses on the correct sequencing of the policy: the formation of specialized human capital and capabilities should precede, or at least occur at the same time as, the programs aimed at increasing the demand for R\&D in the specialized domain in question.

Second, an integrated vision of the transformative activity that must not focus only on the high-tech dimension of the structural change sought. The activity must also integrate actions that allow the adoption of high tech by the sector that will be a potential user. Thus, for example, a transformative activity that concerns a certain number of scientific innovation projects for agriculture must also include the actions (adoptions, training, and management) that will facilitate the adoption of high tech by the traditional sector. If this is not done, the activity will remain limited to start-ups and will lose its truly transformative nature. This principle is important if we want to respond to the objection regarding the increase in the gap between dynamic and non-dynamic sectors of the economy and succeed in making this policy reconcile dynamism or vitality and inclusion. 
Third, how can we be sure that supporting the development of transformative activity will not result in a piling up of useless instruments that are poorly coordinated and ultimately costly? Respecting the previously mentioned design principles-for example, the integrated vision of a priority that involves supporting not only breakthrough innovations but also the management and absorption capacities of sectors that are potential users-is likely to produce an over-elaborate policy. A design principle is essential here. It is the one known as the Tinbergen assignment theorem that provides at least first-order guidance on the "number" of instruments or programs that need to be deployed according to the goals or targets. The number of externalities or market failures should determine the number of instruments (Jaffe et al., 2004). If we again take the transformation of the agri-food sector, there is a need for instruments to support research and start-ups (because of knowledge externalities as well as capital market imperfections) and instruments to support adoption in the traditional sector (because of adoption and network externalities as well as training externalities). Finally, coordination failures can happen at the interface between the high-tech and traditional sectors, and this would also need to be fixed through other instruments (e.g., a platform of specialized services to support transfer of technologies). All in all the support of the transformative activity in this special S3 case should therefore involve about five instruments to be implemented in a coordinated way. And it is because skeptical argument $n^{\circ} 3$ is pertinent—how can the government manage such complexity—that the latter must choose and determine a small number of transformative activities that must be supported. "Doomed to choose," Hausmann and Rodrik (2006) tell us.

\subsection{Experimental policy}

MOPs have an experimental nature. The objectives targeted represent, by definition, experiments; some will work and some will not. We can clearly see the difference in relation to a neutral policy applying a relatively well-managed instrument and whose "treatment effect" is known-for example, an R\&D tax credit available to all companies involved in R\&D. We see that the political risk in this case is low. In view of past experiments and well-managed evaluation methods, we can bet that this policy will be effective in most contexts (i.e., it will lead to an increase in research efforts). It is of course a case appreciated by politicians and policymakers. In the case of a non-neutral policy where the objective is the development of a certain transformative activity, the experiment is much more risky. Each one of the transformative activities initiated is a gamble. These risks imply certain design principles.

First, entrepreneurial discovery: the application of this principle fundamentally reflects the experimental nature of each transformative activity. As concrete exploration and coordination actions advance (projects, partnership, platform, and training), entrepreneurial discovery operates at two levels-projects (success and failure) and the transformative activity in its entirety-is it growing; will it lead to the hoped structural change? The centrality of entrepreneurial discovery in the development of a transformative activity stems from the fact that initially there is no complete knowledge regarding the way in which the process of the emergence and development of this activity is going to unfold. It is as R\&D investments, projects, and coordination actions develop that the potential of the transformative activity and the probabilities of success of the different projects and actions will be revealed. Unlike in the case of a neutral policy, one cannot apply here the standard principal-agent logic that supposes that the government has sufficient information to construct a plan and provide the incentives necessary for firms to carry it out. "What if, as I and many others assume, there are no principals ... with the robust and panoramic knowledge needed for this directive role?" (Sabel, 2004: 3). The fundamental point here is the Hayeckian argument that the knowledge about what to do is not readily apparent. It is knowledge "of time and place" whose emergence cannot be planned in advance. The ex-ante knowledge is incomplete. We talk of entrepreneurial discovery (Kirzner, 1997), as this term comprises a crucial learning dimension regarding the real possibilities of development and structural effect offered by the transformative activities. There are successes, failures, and surprises. Integration of the entrepreneurial discovery concept in an industrial policy design was first achieved by Hausmann and Rodrik (2002). This represents an essential step forward in enabling MOPs to avoid the tragedy of centralized planning, in other words reconciling a logic of strategic choice and priorities with a logic of decentralized and entrepreneurial information and initiatives.

The development of the transformative activity should thus be informed by a discovery process regarding opportunities, constraints, and challenges. As such, the process of entrepreneurial discovery is characterized by a strong learning dimension.

Second, flexibility: the transformative activities thus identified must not be seen as unalterable structures but rather as pioneering ventures and experiments. The flexibility of the strategy is therefore a requirement. What is learned 
thanks to the entrepreneurial discovery must exert a retroactive effect on the characteristics of the programs within each transformative activity and also on the activities themselves to modify or possibly discontinue them. Moreover, new combinations can emerge at any time and must be integrated in the form of new priorities. The flexibility of the strategy imposes control and evaluation mechanisms that are essential for the conducting of the strategy. Monitoring is a key element and any transformative activity needs to be measured to understand performance, the degree of progress, the direction and magnitude of changes, as well as potential failures and structural deficiencies and to indicate that some issues warrant further investigation. One key feature of such indicators is to provide an up-to-the-minute barometer of the activity that can be used for immediate feedback and adjustment of the policy (Feldman et al., 2016). ${ }^{6}$

Third, maximization of spillovers. The social value of a process of entrepreneurial discovery is that it informs the whole system about new opportunities, potential success, and failures; i.e., what are the directions of R\&D and innovation that are likely to generate the desirable structural changes. The maximization of informational spillovers created by the discovery phase is a key design principle that distinguishes entrepreneurial discoveries supported by a public policy, as is the case here, from those made privately within firms that will tend not to diffuse this information. Companies-most often large companies—can internalize the process of entrepreneurial discovery. They are looking for new strategic domains and ways to explore them concretely. However, the difference between a process of entrepreneurial discovery internalized in a company and a process of entrepreneurial discovery embedded in a public policy is obvious. In the former case, the social value of the process will be lower than in the latter.

When the entrepreneurial discovery process is supported by a public policy, it is critical that the informational value of the process be maximized. The companies that are supported in joining the entrepreneurial discovery process must accept and conform to these rules of information and audit. This creates a design issue: the reward for the entrepreneurial discovery should be structured in a way that maximizes the spillovers to the other participants and potential entrants in the transformative activity (Rodrik, 2004).

\subsection{The general nature of the policy design}

This policy based on such design principles is neither purely bottom-up (because at some points priorities are chosen by the government) nor totally top-down (because a few design principles—entrepreneurial discovery process and public-private interactions-introduce a strong bottom-up component). It is rather an intermediate process aiming to enhance entrepreneurial coordination within a framework (a small number of priority areas and transformative activities) structured by the government.

By means of the still very abstract table that summarizes this section, we wish to highlight in the last section some ways of implementing these principles that we find interesting, as they contribute to conveying an optimistic vision of the capacities of governments and agencies to elaborate an MOP-in this case an S3 (Table 1).

\section{From abstract policy design to institutions and practices}

What is described earlier involves the findings of a somewhat abstract policy research. But the concretization of these findings in a specific socioeconomic and political context is particularly demanding in terms of policymaking capability and monitoring competences. S3s will not succeed if policymaking capabilities at a regional level do not reach a high level of competence and commitment. This is no surprise: S3 is part of the so-called new industrial policy family that aims at designing and deploying a rather sophisticated approach to make compatible vertical choices for resource allocation and decentralized market dynamics. Certain key authors are addressing this issue critically (see in particular, Morgan, 2013, 2016).

It is totally obvious that a poor quality of government constitutes a serious barrier to the formulation and application of S3 (Rodriguez-Pose et al., 2014). Of course the aggregate measures of governmental quality tend to convey a

6 Rammer's recent works provide a good basis for the development of subsidy mechanisms for R\&D projects allowing a certain flexibility in the allocation of resources: instead of one single financing decision, made at the start of the project, Rammer elaborates a multiple and sequential decision model that allows projects that are not working to be interrupted sooner and the volume of financing allocated to those that are progressing to be increased (Rammer and Klingebiel, 2012). 
Table 1. Main design principles for a Mission-Oriented Policy

\begin{tabular}{ll}
\hline Generic problems & Design principles \\
\hline $\begin{array}{l}\text { Establishing priorities (non-neutrality and directionality } \\
\text { in resource allocation) }\end{array}$ & \\
& Level of granularity \\
& Public-private interactions-transparency
\end{tabular}

Developing a transformative activity (system approach)

Human capital—demand for R\&D sequence

Integrated vision-vitality and inclusion-innovation and diffusion

Tinbergen assignment

Recognizing and implementing the implications of an experimental policy (governance)

Entrepreneurial discovery

Flexibility and monitoring

Maximization of spillovers

somewhat pessimistic vision (Rodriguez-Pose et al., 2014) and well-documented studies, for example, concerning Central European and East European regions, highlight all the institutional deficits and capacity deficits that penalize the implementation of S3 (Karo et al., 2017). We can also however identify a certain number of regional accomplishments, undertaken in the spirit of policy design presented earlier, and that express the capacity of regional institutions to design and implement mission-oriented programs.

Thus, the identification and selection of priorities and transformative activities has in most European regions given rise to exemplary processes of interactions between the public and private sectors, prepared by the elaboration of a systematic knowledge base concerning economic structures, innovation capacities, and entrepreneurial resources. Thanks to this base, activities linking existing capacities and new opportunities are identified and selected. There are numerous examples of regions that for the first time have set up public-private forums and relatively transparent processes for establishing priorities. One fundamental result is that the very process of designing a strategy has generated beneficial effects resulting from the commitment of regions to the policy process. For instance, regions know themselves better today than before because self-assessment and evaluation of potentials and capacities were required (Kroll, 2016).

The development of transformative activities has in certain regions shown a capacity to comply with the correct sequences (training and R\&D) and have an integrated vision combining high-tech objectives and diffusion objectives in the traditional sector. Therefore, in the case of the Basque Country (Spain), the transformative activity focusing on the digitalization of traditional mechanical industries includes programs dealing with training, R\&D, the adoption of new technologies, the coordination of services (platform), and finally the setting up of international partnerships (Navarro et al., 2011).

In the case of Lombardy (Italy), the transformative activity focusing on innovations in agriculture has integrated a collection of actions to support the absorption and adoption of new knowledge and technologies offered by startups. We have already mentioned this example in the previous section. The point here-if we again take the agriculture case-is to involve the agri-food sector as a huge reservoir of potential adopters of these new technologies. The goal is therefore twofold: encourage young innovative firms by equipping their ecosystem with all the necessary capabilities and address the innovational complementarities between the high-tech and traditional sectors. The latter goal involves addressing human capital and capability problems, fixing the adoption externalities, addressing coordination failures, and providing some specific public goods; in other words, it will address many barriers and obstacles to innovation diffusion in a traditional sector. The choice for the Lombardy region was therefore between helping a few nice guys with brilliant ideas or undertaking the proper actions to support the development of a real transformative activity, which would be likely to drive structural changes—not only in the high-tech but also in the huge agrifood sector (Foray, 2017).

Recognition of the experimental nature of the MOP is without doubt the most difficult problem and its implications (entrepreneurial discovery, flexibility, and information dissemination) are still little understood or appreciated 
by policymakers. Of course the expression "entrepreneurial discovery" has become standard in European regions and European Union (EU) bodies, but this is more a matter of rhetoric than substance. What does this involve in concrete terms? Providing firms with incentives to explore the new opportunities, without dictating to them the content or direction of their projects, provided that these projects fall within the framework of the transformative activity in question; continuously evaluating progress, blockages, and surprises; ensuring the diffusion of information to the industrial base concerned; and reacting to the entrepreneurial discovery process by making decisions regarding the continuity or interruption of projects (according to Rammer's logic of flexibility, footnote 5). We see these principles being put into place in certain regions. Morgan (2016) describes for example the creation of "new 'entrepreneurial discovery spaces' where public and private partners can explore and monitor projects of mutual interest." $\mathrm{He}$ observes this in the case of the Basque Country; we have also observed it in many other regions.

Thus, new practices and institutions are emerging, confirming the formation of new capacities at government and agency levels to design and implement an S3-type MOP. The basic problem-that of introducing decentralized information and entrepreneurial processes within a policy that determines targets and objectives in a centralized manner-seems to have been relatively well resolved in many cases. In the most advanced regions and those with a rich tradition of industrial policy, we can assume that regional government capacities are equal to the demands of policy design and that any problems encountered originate more from historical conditions regarding the setting up of $\mathrm{S}^{7}$ than from the government's level of capacity. In the case of intermediary regions, we notice that certain actors are called upon to play a central role, especially the technological universities or engineering departments of universities. In the favorable case where these departments play a historical role of knowledge transfer and collaboration with industry, they can play a central role in the development of the transformative activity (coordination, training, and research) and the development of an experimental culture (entrepreneurial discovery, spillovers, and flexibility). We have examples where nothing would be possible without the priceless contribution of university R\&D laboratories. We then observe a logic of co-specialization whereby the university both influences and takes into consideration the region's transformative activities to choose its research orientations (Bonaccorsi, 2016). This is the case for example of Franche-Comté (France).

\section{Conclusion}

This article has developed the case of S3, recently adopted and implemented in Europe as part of the EU's cohesion policies, to examine the way in which an MOP and the complex policy design that it implies have been designed and put into practice by the regions concerned. This practical application implies new structures, a new culture, and new mechanisms on the part of government agencies that we consider must be fundamentally associated with these new types of mission policy.

The establishment of priorities (according to the analysis of the desired structural changes, the comparison between existing capacities and opportunities, and the identification of the correct level of granularity), the development of transformative activities corresponding to these priorities (which involves the deployment of various instruments to respond to the different obstacles and difficulties, observing the right sequences, and integrating innovation and diffusion), and finally recognition of the experimental dimension of this policy (entrepreneurial discovery, flexibility and monitoring, and spillovers) all represent challenges that must encourage public agencies to invent new structures and change their political practices and culture.

Numerous cases show that the interim assessment is not negative. Many regions have been able to adapt or transform their policy process to respond to some of these challenges. A new policy mind-set is slowly being instilled into policymakers-comprising prioritization and vertical choice instead of neutral and horizontal programs; decentralization, self-discovery, and flexibility rather than central planning; and transformative activities rather than sectoral priorities. It seems to us that it is an important message in view of the resurgence of these new missionoriented and new industrial policies.

7 Remember that there has been no pilot phase or trial period-each region had to suddenly implement a policy that was in many ways new to everyone-governments and experts alike. 


\section{Acknowledgements}

The author is indebted to one reviewer for very valuable comments as well as to the two editors-Rainer Kattel and Mariana Mazzucato-for their great support, encouragement, and suggestions.

\section{References}

Agencia de Inovaçao (ADI). (2012), Portuguese Footwear Industry Improved Its Competitiveness through RひD. Agencia de Inovaçao: Portugal.

Aghion, P. (2016), Entrepreneurship and Growth: Lessons from an Intellectual Journey. Entrepreneurship Prize Award Lecture: Stockholm.

Aghion, P., P. A. David and D. Foray (2009), 'Science, technology and innovation for economic growth: linking policy research and practice in STIG systems,' Research Policy, 38(4), 681-693.

Bonaccorsi, A. (2016), 'Addressing the disenchantment: universities and regional development in peripheral regions,' Journal of Economic Policy Reform, 20(4), 293.

Bresnahan, T. (2010), 'General purpose technologies,' in B. Hall and N. Rosenberg (eds), Handbook Economics of Innovation. North Holland: Amsterdam, The Netherlands; Oxford, UK.

David, P. A. (1993), 'The theoretical and conceptual setting,' in L. Soete and A. Arundel (eds), An Integrated Approach to European Innovation and Technology Diffusion Policy. European Commission: Brussels, Belgium; Luxembourg, Luxembourg.

Enos, J. (1995), In Pursuit of Science and Technology in Sub-Saharan Africa. UNU/INTECH Studies in New Technology and Development. Routledge: London, UK; New York, NY.

European Commission. (2017), Strengthening Innovation in Europe's Regions: Strategies for Resilient, Inclusive and Sustainable Growth. Communication from the Commission to the European Parliament, the Council, the European Economic and Social Committee and the Committee of the Regions, 264. European Commission: Brussels, Belgium.

Feldman, M., T. Hadjimichael, T. Kemeny and L. Lanahan (2016), 'The logic of economic development: a definition and model for investment,' Environment and Planning C: Government and Policy, 34(1), 5-21.

Foray, D. (2015), Smart Specialisation: Opportunities and Challenges for Regional Innovation Policy. Routledge: London, UK; New York, NY.

Foray, D. (2017), Smart Specialization, Edmund Phelps and the Palazzo Lombardia', in J. Severijns (ed.), Solving Contradictions by Connectivity. Province of Limburg: Maastricht, The Netherlands.

Foray, D., D. C. Mowery and R. R. Nelson (2012), 'Special issue: the need for a new generation of policy instruments to respond to the grand challenges,' Research Policy, 41(10), 1697-1792.

Foray, D., P. A. David and B. Hall (2009), 'Smart specialisation: the concept,' in Knowledge for Growth: Prospects for Science, Technology and Innovation. Report, EUR 24047. European Commission: Brussels, Belgium.

Ghemawat, P. (2017), 'Market and Management Failures,' Capitalism and Society, 12(1), Article 2.

Hausmann, R. and D. Rodrik (2002), 'Economic development as self-discovery,' NBER Working Paper Series, No. 8952. National Bureau of Economic Research: Cambridge, MA.

Hausmann, R. and D. Rodrik (2006), 'Doomed to choose: industrial policy as predicament,' First Blue Sky Seminar, Center for International Development. Harvard University: Cambridge, MA.

Henderson, R. and R. Newell (2010), Accelerating Innovation in Energy: Insights from Multiple Sectors. The University of Chicago Press: Chicago, IL.

Jaffe, A. (2011), Technology Policy and Climate Change. The Next Round of Climate Economics and Policy Research: Washington DC.

Jaffe, A., R. Newell and R. Stavins (2004), 'A tale of two market failures,' Discussion Paper, Resources for the Future: Washington D.C.

Karo, E., R. Kattel, and A. Cepilovs (2017), 'Can smart specialization and entrepreneurial discovery be organized by the Government? Lessons from central and eastern Europe?,' in S. Radosevic (eds), Advance in Theory and Practice of Smart Specialization. Elsevier Science Publishers: Amsterdam, The Netherlands.

Kirzner, I. (1997), 'Entrepreneurial discovery and the competitive market process: an Austrian approach,' Journal of Economic Literature, 35(1), 60-85.

Kremer, M. and H. Williams (2009), 'Incentivizing innovation: adding to the toolkit,' Innovation Policy and the Economy, 10, 1-18.

Kroll, H. (2016), Final Results of the Fraunhofer ISI-RIS3 Survey 2016, Fraunhofer ISI: Karlsruhe, Germany.

Krueger, A. (2012), 'Comments on “new structural economics” by Justin Yfu Lin,' in The World Bank Research Observer. The World Bank: Washington DC.

Matsuyama, K. (1997), 'Economic development as coordination problems,' in M. Aoki (ed.), The Role of Government in East Asian Economic Development. Clarendon Press: Oxford, UK.

Mazzucato, M. (2011), The Entrepreneurial State. Demos: London, UK. 
Morgan, K. (2013), 'The regional state in the era of smart specialization,' Ekonomiaz, 83(2), 102-124.

Morgan, K. (2016), 'Nurturing novelty: regional innovation policy in the age of smart specialization,' Environment and Planning C: Politics and Space, 35(4), 569-583.

Mowery, D. C. and T. Simcoe (2002), 'Is the internet a US invention? An economic and technological history of computer networking,' Research Policy, 31(8-9), 1369-1387.

Murray, F., S. Stern, G. Campbell and A. MacCormack (2012), 'Grand innovation prizes: a theoretical, normative, and empirical evaluation,' Research Policy, 41(10), 1779-1792.

Navarro, M., M. J. Aranguren and E. Magro Montero (2011), 'Smart Specialisation Strategies: the Case of the Basque Country,' Orkestra Working Paper Series in Territorial Competitiveness, No. 2011-R07. Orkestra: San Sebastian.

Phelps, E. (2006), Macroeconomics for a Modern Economy. Nobel Prize Lecture. Stockholm, Sweden.

Rammer, C. and R. Klingebiel (2012), Public Funding of Innovation Projects: Is It Time for a More Flexible Approach? ZEW Policy Brief, No. 2, Center for European Economic Research (ZEW): Mannheim, Germany.

Rodriguez-Pose, A., M. di Cataldo and A. Rainoldi (2014), The Role of Government Institutions for Smart Specialisation and Regional Development. JRC Technical Reports, S3 Policy Brief Series, n04/2014, Publication Office of the European Union: Luxemburg, Luxembourg.

Rodrik, A. (2007), 'Normalizing Industrial Policy,' Commission on Growth and Development.

Rodrik, A. (2013), 'Green industrial policy,' Grantham research Institute project on Green growth and the New Industrial Revolution. Oxford Review of Economic Policy, 30(3), 469-491.

Rodrik, D. (2004), 'Industrial policy for the twenty-first century,' CEPR, Discussion Paper Series, No. 4767. Center for Economic Policy Research: London.

Romer, P. (2000), 'Should the government subsidize supply or demand in the market for scientists and engineers?,' Innovation Policy and the Economy, 1, 221-252.

Sabel, C. (2004), Beyond Principal-Agent Governance: Experimentalist Organizations, Learning and Accountability. Columbia University Press: New York, NY.

Stiglitz, J. and S. Wallsten (1999), 'Public-private technology partnerships,' The American Behavioral Scientist, 43(1), 52-73.

Trajtenberg, M. (2002), 'Government support for commercial R\&D: lessons from the Israeli experience,' Innovation Policy and the Economy, 2, 79-134. 